Short communication

\title{
Comparison of infectivity and virulence of clones of Trypanosoma evansi and Ttrypanosoma equiperdum Venezuelan strains in mice
}

\author{
Perrone T. ${ }^{\mathrm{a}, \mathrm{b}, 1}$, Aso P.M. ${ }^{\mathrm{b}}$, Mijares A. ${ }^{\mathrm{a}}$, Holzmuller P. ${ }^{\mathrm{c}}$, Gonzatti M. ${ }^{\mathrm{b}}$, Parra N. ${ }^{\mathrm{a}, *}$ \\ ${ }^{a}$ Laboratorio de Fisiología de Parásitos, Centro de Biofísica y Bioquímica, Instituto Venezolano de Investigaciones Científicas, Altos de Pipe, 1020A, Venezuela

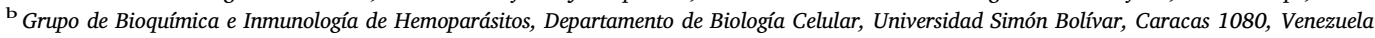 \\ c CIRAD, UMR CIRAD-INRA CMAEE, UMR CIRAD-IRD INTERTRYP, Montpellier, France
}

\section{A R T I C L E I N F O}

\section{Keywords:}

Trypanosoma evansi

Trypanosoma equiperdum

Clones

Infectivity

Virulence

\begin{abstract}
A B S T R A C T
Livestock trypanosomoses, caused by three species of the Trypanozoon subgenus, Trypanosoma brucei brucei, $T$. evansi and T. equiperdum are widely distributed and limit animal production throughout the world. The infectivity and virulence of clones derived from Trypanosoma evansi and Trypanosoma equiperdum Venezuelan strains were compared in an in vivo mouse model. Primary infectivity and virulence determinants such as survival rates, parasitemia levels, PCV, and changes in body weight and survival rates were monitored for up to 32 days. The T. equiperdum strain was the most virulent, with $100 \%$ mortality in mice, with the highest parasitemia levels $\left(7.0 \times 10^{7}\right.$ Tryps $\left./ \mathrm{ml}\right)$ and loss of physical condition. The T. evansi strains induced $100 \%$ and $20 \%$ fatality in mice. Our results show that the homogeneous parasite populations maintain the virulent phenotype of the original $T$. equiperdum and T. evansi stocks. This is the first comparative study of infectivity and virulence determinants among clonal populations of T. equiperdum and T. evansi.
\end{abstract}

\section{Introduction}

Trypanosoma evansi and Trypanosoma equiperdum, are closely related, distinct parasites, that have been classified either with the binomial nomenclature (Hoare, 1972; Desquesnes et al., 2013; Carnes et al., 2015; Wen et al. 2016) or the trinomial nomenclature (Claes et al., 2006). T. evansi is a blood and extracellular parasite that causes equine trypanosomosis, a disease known as Surra in Africa or Derrengadera in South America. Traditionally, T. evansi infections have been observed in domestic and wild animals in acute, sub-acute and chronic forms, depending on the virulence of the strain and the parasite-host interplay. Horses and camels, but also donkeys, mules, llamas, dogs, cats, cattle, and buffalo, are susceptible hosts of economic interest (Desquesnes et al., 2013). Other wild mammals, such as capybaras (Hydrochoerus hydrochaeris), act as reservoir hosts (Perrone et al., 2009). The clinical signs of T. evansi infection include anemia, recurrent fever, weight loss, emaciation, swelling of the hind limbs and hemostatic abnormalities (Holland et al., 2003; Mekata et al., 2013). T. equiperdum causes a venereal disease known as Dourine in horses and donkeys and is morphologically indistinguishable from other Trypanozoon species (Verducci et al., 1989; Brun et al., 1998). These host species appear to be the only natural reservoirs for T. equiperdum. Dogs, rabbits, rats, and mice are susceptible to experimental infections (Spickler et al., 2009). Dourine has been found in Africa, Asia, Russia, Mexico, Southern and Eastern Europe, and several outbreaks in Italy have been reported in recent years (Dávila and Silva, 2000; Wei et al., 2011; Calistri et al., 2013; Pascucci et al., 2013, Vulpiani et al., 2013). Dourine is a serious, often chronic, venereal disease characterized mainly by swelling of the genitalia, cutaneous plaques, and neurological signs. The symptoms vary with the virulence of the strain, the nutritional status of the host, and stress factors.

Pathogenicity is the aptitude of an organism to produce clinical signs of different severity including mortality and is determined by its infectivity and virulence. For parasites, virulence depends on the capacity to multiply inside a host, while infectivity has been defined as the ability of the microorganism to multiply and be maintained in a given host (Holzmuller et al., 2008a). Based on the median survival time, trypanosome virulence has been classified as extreme, when death occurs within a week, while high, death within a month, moderate, death within several months and low, chronic infection and mild or no clinical signs (Herbert and Parratt, 1979). Comparative virulence studies of T. evansi isolates from water buffaloes have been carried out in mice (Verdillo et al., 2012). Other authors have reported clear differences in virulence and/or pathogenicity for T. congolense strains or

\footnotetext{
* Corresponding author.

E-mail address: njparra@ivic.gob.ve (P. N.).

${ }^{1}$ Deceased.
} 
isolates in bovines (Bengaly et al., 2002a,b; Masumu et al., 2006) and in mice (Bengaly et al., 2002a), for T. brucei gambiense strains in Balb/c mice (Holzmuller et al., 2008a) and T. congolense and T. evansi in nude rats (Holzmuller et al., 2008b). The goal of the study was to compare the infectivity and virulence, in terms of parasitemia levels, clinical signs and survival rates of mice infected with clones derived from $T$. evansi and T. equiperdum strains, that were isolated from three different hosts in Venezuela.

\section{Materials and methods}

Two T. evansi strains (TeAp-ElFrio01, from capybara and TeGuTerecay323, from donkey) and one T. equiperdum strain (TeAp-N/D1, from horse) were used in this study (Perrone et al., 2009; Sánchez et al., 2015a,b). To obtain homogenous trypanosome populations, NMRI mice were immunosuppressed with cyclophosphamide (Endoxan, $300 \mathrm{mg} /$ $\mathrm{kg}) 48 \mathrm{~h}$ prior to infection with 1 trypomastigote/mouse (Smith et al., 1982). When parasitemia reached $1 \times 10^{6} \mathrm{tryp} / \mathrm{ml}$, mice were bled to obtain the parasites and two similar passages were performed.

For experimental infections, forty male, 12 weeks old NMRI inbred mice, were inoculated subcutaneously with 1 trypomastigote/mouse according to the ethical guidelines of the "Código Nacional de Ética para La Vida and the Manual de Ética para la Producción y Uso de Animales de Laboratorio (MPPEUCT-Universidad Central de Venezuela-Facultad de Ciencias, 2011)". Parasitemia level, hematocrit \%, and body weight were recorded every two days and compared to the control group. Mice deaths were registered daily. All experiments were performed in triplicate and the means and standard errors were determined. The arithmetic means of the infected and the control group were calculated over the course of the experiment, and analyzed by the non-parametric, one-way Analysis of Variance (ANOVA); P $<0.05$ was considered significant.

\section{Results}

Mice infected with the $T$. equiperdum clone showed rapidly increasing parasitemia up to day 8 , while the groups infected with the two T. evansi clones showed lower and fluctuating parasitemias (Fig. 1a). According to the prepatent periods for each of the strains, the TeAp-N/D1 clone can be considered as extremely virulent (2 days), TeAp-ElFrio01 as moderately virulent ( 5 days) and TeGu-Terecay323 is a low virulence clone (8 days).

The survival of mice curves presented in Fig. 1b show that the highest \% survival was observed for the T. evansi clone TeGu-Terecay323 (80\%). In contrast, the TeAp-ElFrio01 and T. equiperdum TeApN/D1 clones rendered $100 \%$ mortality. Several infectivity and virulence parameters were evaluated for each strain throughout the mice experimental infections (Table1).

The development of anemia is shown in Fig. 1c. In the mice infected with TeAp-ElFrio01, the average hematocrit decreased 15\% with respect to the values at the beginning of the infection. In contrast, in the infection with TeGu-Terecay323, the mean hematocrit decreased by $3 \%$. In mice infected with the TeAp-N/D1, the mean hematocrit decreased rapidly and significantly (22\%) until day 8 post-infection, when mice died. No anaemia was observed in the control group.

Body weight loss was rapid in mice infected with the T. equiperdum clone and correlated with its extreme virulence. A decreasing trend in body weight was observed in the group of mice infected with the moderately virulent T. evansi. For the low virulent T. evansi clone, no changes in body weight were observed, and this trend correlated with the maintenance of hematocrit values

\section{Discussion}

In order to evaluate the infectivity and virulence of clonal populations of $T$. equiperdum and T. evansi, we focused this study on a parasitological and clinical observation of experimental infection in a susceptible mice model. The rapid death of the group infected by the $T$. equiperdum clone can be attributed to the rapid propagation and high parasitemia levels that translate into energy requirements that exceed the capacity of the host. Both T. evansi and T. equiperdum are mainly extracellular parasites, the success of the infection is based on the "crosstalk" with the host immune cells through the release of molecules that play a key role on the course and immunopathology of the disease. T. brucei gambiense has been shown to promote the release of cytokines such as tumor necrosis factor (TNF), gamma interferon (IFN- $\gamma$ ) and interleukins by macrophages (Holzmuller et al., 2008a). In mice infected with $\mathrm{T}$. brucei, these molecules appear to have toxic effects on the endocrine system of the host (Bosschaerts et al., 2010). Furthermore, IFN- $\gamma$ produced by $\mathrm{CD}^{+} \mathrm{T}$ cells acts as a growth factor in $T$. congolense (Holzmuller et al., 2008a,b). Likewise, T. brucei secretometriggered BMDCs inhibit LPS-stimulated production of TNF- $\alpha$ and IL- 6 proinflammatory cytokines, as well as IL-10. These cytokines are key mediators of Th1 and Th2 responses and are directly involved in the induction of an acquired immune response. The decrease of these cytokines favors parasite growth in the host (Garzón et al., 2013).

In the T. equiperdum mice infection, the sharp hematocrit decrease correlated with high parasitemias and accelerated death. In T. evansi infections, anemia was observed only in TeAp-ElFrio01. The hematocrit decrease is the most common feature in infections by Salivarian trypanosomes and is used as one of the main disease indicators. It has been described in several hosts of different trypanosomes, including sheep, dogs, coatis and camels (Audu et al., 1999; Reid and Husein, 2001; Herrera et al., 2002; Masumu et al., 2006). The mechanisms that underlie anemia have not been fully elucidated and the pathogenesis caused by these trypanosomatids is extremely complex, multifactorial and appears to include the host response. Several theories have been proposed to explain the anemia that accompanies animal trypanosomosis caused by T. evansi. According to Juyal (2002), anemia is a consequence of the host immunological response. They propose that erythrocytes acquire trypanosome antigens, which triggers an immunological reaction and recognition by complement. de Menezes et al. (2004) propose three alternative hypothesis, hemolysis due to the mechanical action of the parasites on the red blood cells, the increase of endocytosis by spleen cells or intravascular clotting due to microvascular lesions and hemolysis. Dargantes et al. (2005) propose that the anemia observed in goats infected by $T$. evansi is caused by the massive destruction of red blood cells by the mononuclear phagocytic system.

Together with the anemia, observation of body weight, rough hair coat and behavior are important parameters to be considered in trypanosome infections. Weight loss in murine models infected with $T$. evansi is due to appetite loss, which in turn results in lipid and copper deficiencies (Desquesnes et al., 2013). Lipids are needed for natural mice hair coat, while lusterless hair coat has been observed in mice infected with either highly virulent or moderately virulent strains (Verdillo et al., 2012). In agreement with previous reports of experimental mice and rat T. equiperdum infections, that showed anemia, and progressive loss of condition, mice infected with the TeAp-N/D1 cloned strain did not show local oedema of the genitalia, the mammary glands or oedematous cutaneous eruptions, typical of Dourine (Scacchia et al., 2011; Hagos et al., 2010). The absence of these clinical signs of Dourine may be due to the high mortality and virulence of this strain which results in a very short life for the infected mice.

Biological and pathological features observed upon infection with the T. equiperdum and T. evansi strains were maintained throughout the stages of cloning (1, 2 and 3, data not shown) and were consistent with the infectivity and virulence characteristics of the heterogeneous strains from which they originated (Holzmuller et al., 2008b). These findings suggest that the infectious phenotype appears to be stable in a cloned population; while plasticity of trypanosome infectivity probably occurs at the population level due to parasite adaptation during transmission cycles over the years. 

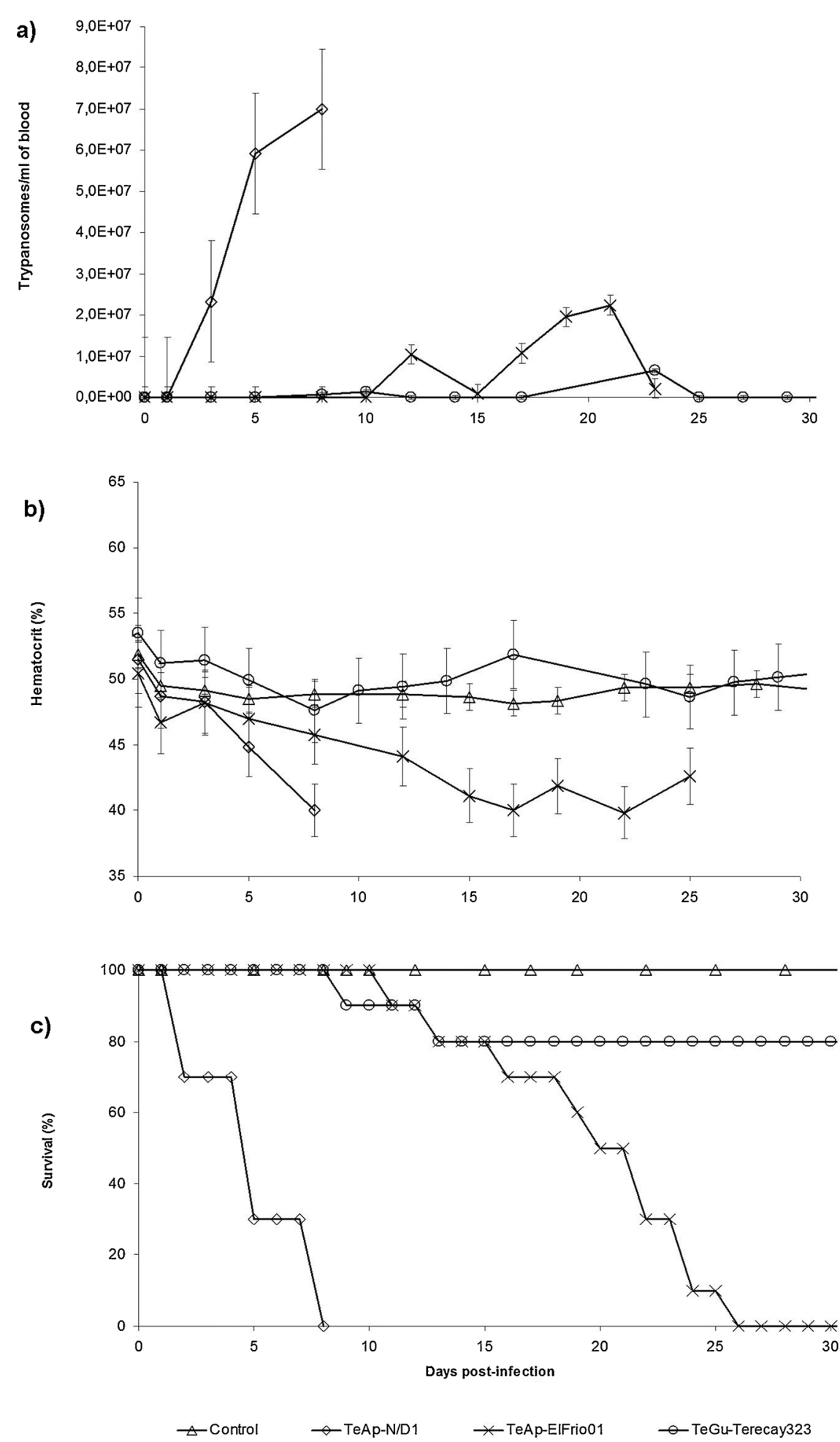

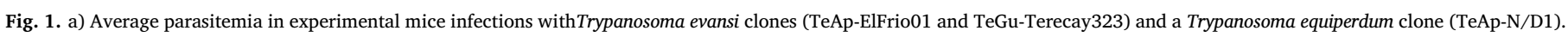

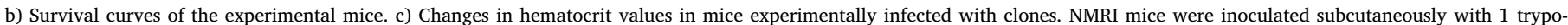
mastigote of either T. evansi or T. equiperdum cloned strains. A group of non-infected mice was used as control. Mice survival rates were registered daily.

\section{Conclusion}

Clones derived from the recently characterized Latin American $T$. equiperdum strain TeAp-ND1 maintained the highly virulent and pathological features of the strain, but clinical signs of Dourine were not shown through the experimental infection since mice died within a short period, due to the high infectivity of the strain. Some of the clinical signs in the mice experimentally infected with the T. equiperdum clone, including anemia, progressive weight loss, and body condition, were similar to those observed with one of the T. evansi clones (i. e. TeAp-ElFrio01). On the contrary, the clone from the TeGu-Terecay323 T. evansi strain caused asymptomatic disease, no significant alteration of hematocrit values and very low parasitemias. The differences in virulence and infectivity between the T. evansi and T. equiperdum clones are consistent with the genetic heterogeneity of these species or subspecies, as reported by Wei et al., 2011; Verdillo et al., 2012; 
Table 1

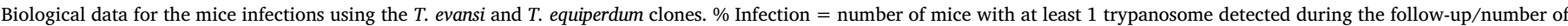

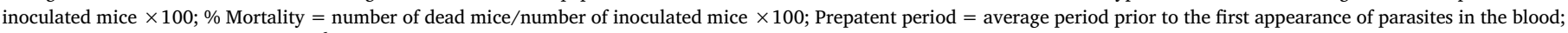
Maximum parasitemia reached $\left(\times 10^{6}\right.$ trypanosomes $\left./ \mathrm{ml}\right)$.

\begin{tabular}{|c|c|c|c|c|c|c|}
\hline Strain & $\begin{array}{l}\mathbf{N}^{\circ} \text {.mice } \\
\text { inoculated }\end{array}$ & $\begin{array}{l}\text { Prepatent period } \\
\text { (days) }\end{array}$ & Infection (\%) & Mortality (\%) & $\begin{array}{l}\text { Period of mortality } \\
\text { (Days) }\end{array}$ & $\begin{array}{l}\text { Maximum parasitaemia }\left(\times 10^{6}\right. \\
\text { trypanosomes } / \mathrm{ml} \text { blood })\end{array}$ \\
\hline TeAp-N/D1 & 10 & 2 & 100 & 100 & 8 & 89.8 \\
\hline TeAp-El Frío01 & 10 & 5 & 100 & 100 & 25 & 59.9 \\
\hline TeGu-Terecay323 & 10 & 8 & 40 & 20 & 31 & 6.48 \\
\hline
\end{tabular}

Desquesnes et al., 2013; Carnes et al., 2015; Sánchez et al., 2015a,b.

\section{Conflict of interests}

The authors declare that they have no conflict of interests.

\section{Authors' contributions}

NP propagated the Trypanosoma evansi and Trypanosoma equiperdum strains and obtained the clones used in this study. Analyzed the clinical -hematological parameters throughout the course of the mice infections and contributed to the manuscript draft. TP initiated the molecular characterization of the strains, directed the cloning and the clinical evaluation of the mice infections. PMA conceived the cloning and characterization of the strains. AM participated in the experimental design of the cloning of the strains and contributed to the manuscript draft. PH participated in the experimental design and analysis of all the results and contributed to the manuscript draft. MG participated in the experimental design and contributed to the manuscript draft. All authors read and approved the final manuscript.

\section{Acknowledgements}

This research was supported by grants from FONACIT No. 2004000400 RIDMOH, Misión Ciencia2007001425, Ecos NordPI2008002104, GID21-USB, Instituto Venezolano de Investigaciones Científicas (IVIC) No. 1365. We thank to Dr. Howard Takiff from Instituto Venezolano de Investigaciones Científicas for critically reading this manuscript.

\section{References}

Audu, P.A., Esievo, K.A., Mohammed, G., Ajanusi, O.J., 1999. Studies of infectivity and pathogenicity of an isolate of Trypanosoma evansi in Yankasa sheep. Vet. Parasitol. 86, 185-190.

Bengaly, Z., Sidibe, I., Boly, H., Sawadogo, L., Desquesnes, M., 2002a. Comparative pathogenicity of three genetically distinct Trypanosoma congolense-types in inbred Balb/ c mice. Vet. Parasitol. 2, 111-118.

Bengaly, Z., Sidibe, I., Ganaba, R., Desquesnes, M., Boly, H., Sawadogo, L., 2002b. Comparative pathogenicity of three genetically distinct Trypanosoma congolense in cattle: clinical observations and haematological changes. Vet. Parasitol. 108, 1-19.

Bosschaerts, T., Guilliams, M., Stijlemans, B., Morias, Y., Engel, D., Tacke, F., Hérin, M., De Baetselier, P., Beschin, A., 2010. Tip-DC development during parasitic infection is regulated by IL-10 and requires CCL2/CCR2, IFN-gamma and MyD88 signaling. PLoS Pathog. 6 (8).

Brun, R., Hecker, H., Lun, Z.R., 1998. Trypanosoma evansi and Trypanosoma equiperdum: distribution, biology, treatment and phylogenetic relationship (a review). Vet. Parasitol. 79, 95-107.

Calistri, P., Narcisi, V., Atzeni, M., De Massis, F., Tittarelli, M., Mercante, M.T., Ruggieri, E., Scacchia, M., 2013. Dourine reemergence in Italy. J. Equine Vet. Sci. 33, 83-89.

Carnes, J., Anupama, A., Balmer, O., Jackson, A., Lewis, M., Brown, R., Cestari, I., Desquesnes, M., Gendrin, C., Hertz-Fowler, C., Imamura, H., Ivens, A., Kořený, L., Lai, D.H., MacLeod, A., McDermott, S.M., Merritt, C., Monnerat, S., Moon, W., Myler, P., Phan, I., Ramasamy, G., Sivam, D., Lun, Z.R., Lukeš, J., Stuart, K., Schnaufer, A., 2015. Genome and phylogenetic analyses of Trypanosoma evansi reveal extensive similarity to T. brucei and multiple independent origins for dyskinetoplasty. PLoS Negl. Trop Dis. 9 (1), e3404.

Claes, F., Dujardin, J.C., Touratier, L., Büscher, P., Goddeeris, B.M., 2006. Response to Li et al. and Shaw: return of the ring; opportunities to challenge a hypothesis. Trends Parasitol. 22, 58-59.

Dargantes, A.P., Reid, S.A., Copeman, D.B., 2005. Experimental Trypanosoma evansi infection in the goat. I. Clinical signs and clinical pathology. J. Comp. Pathol. 33 (4),
$261-266$.

Dávila, A., Silva, R., 2000. Animal tripanosomiasis in South America, current status, partnership and information technology. Ann. N. Y. Acad. Sci. 916, 199-212.

de Menezes, V.T., Queiroz, A.O., Gomes, M.A., Marques, M.A., Jansen, A.M., 2004. Trypanosoma evansi in inbred and Swiss-Webster mice: distinct aspects of pathogenesis. Parasitol. Res. 94 (3), 193-200.

Desquesnes, M., Holzmuller, P., Lai, D.H., Dargantes, A., Lun, Z.R., Jittaplapong, S., 2013. Trypanosoma evansi and Surra: a review and perspectives on origin, history, distribution, taxonomy, morphology, hosts, and pathogenic effects. Biomed. Res. Int. $1-20$.

Garzón, E., Holzmuller, P., Bras-Gonçalves, R., Vincendeau, P., Cuny, G., Lemesre, J.L., Geiger, A., 2013. The Trypanosoma brucei gambiense secretome impairs lipopolysaccharide-induced maturation, cytokine production, and allostimulatory capacity of dendritic cells. Infect. Immun. 81 (9), 3300-3308.

Hagos, A., Goddeeris, B.M., Yilkal, K., Alemu, T., Fikru, R., Yacob, H.T., Feseha, G., Claes, F., 2010. Efficacy of cymelarsan and diminasan against Trypanosoma equiperdum infections in mice and horses. Vet. Parasitol. 171 (3-4), 200-206.

Herbert, W.J., Parratt, D., 1979. Virulence of trypanosomes in the vertebrate host. In: Lumsden, W.H.R., Evans, D.A. (Eds.), Biology of Kinetoplastida. Academic Press, New York, pp. 482-521.

Herrera, H.M., Alessi, A.C., Marques, L.C., Santana, A.E., Aquino, L.P., Menezes, R.F., Moraes, M.A., Machado, R.Z., 2002. Experimental Trypanosoma evansi infection in South American coati (Nasua Nasua): hematological, biochemical and histopathological changes. Acta Trop. 81 (3), 203-210.

Hoare, C.A., 1972. The Trypanosomes of Mammals. A Zoological Monograph. Blackwell Scientific Publication, Oxford and Edinburgh.

Holland, W.C., Do, T.T., Huong, N.T., Dung, N.T., Thanh, N.G., Vercruysse, J., Goddeeris, B.M., 2003. The effect of Trypanosoma evansi infection on pig performance and vaccination against classical swine fever. Vet. Parasitol. 111, 115-123.

Holzmuller, P., Biron, D.G., Courtois, P., Koffi, M., Bras-Gonçalves, R., Daulouède, S., Solano, P., Cuny, G., Vincendeau, P., Jamonneau, V., 2008a. Virulence and pathogenicity patterns of Trypanosoma brucei gambiense field isolates in experimentally infected mouse: differences in host immune response modulation by secretome and proteomics. Microbes Infect. 1, 79-86.

Holzmuller, P., Grébaut, P., Peltier, J.B., Brizard, J.P., Perrone, T., Gonzatti, M., Bengaly, Z., Rossignol, M., Aso, P.M., Vincendeau, P., Cuny, G., Boulangé, A., Frutos, R., 2008b. Secretome of animal trypanosomes. Ann. N. Y. Acad. Sci. 1149, 337-342.

Juyal, P.D., 2002. Newer Perspectives in the Diagnosis and Control of Trypanosomosis (Surra) in Domestic Livestock in India. Department of Veterinary Parasitology College of Veterinary Science, Punjab Agricultural University, Ludhiana, India. http:// citeseerx.ist.psu.edu/viewdoc/download?doi=10.1.1.609.520\&rep = rep1\&type $=$ pdf.

Masumu, J., Marcotty, T., Geysen, D., Geerts, S., Vercruysse, J., Dorny, P., den Bossche, P.V., 2006. Comparison of the virulence of Trypanosome congolense strains isolated from cattle in a Trypanosomiasis endemic area of eastern Zambia. Int. J. Parasitol. 4, 497-501.

Mekata, H., Konnai, S., Mingala, C.N., Abes, N.S., Gutierrez, C.A., Dargantes, A.P., Witola, W.H., Inoue, N., Onuma, M., Murata, S., Ohashi, K., 2013. Isolation, cloning, and pathologic analysis of Trypanosoma evansi field isolates. Parasitol. Res. 112 (4), 1513-1521.

Pascucci, I., Di Provvido, A., Cammà, C., DI Francesco, G., CalistrI, P., Tittarelli, M., Ferri, N., Scacchia, M., Caporale, V., 2013. Diagnosis of dourine outbreaks in Italy. Vet. Parasitol. 193, 30-38.

Perrone, T.M., Gonzatti, M.I., Villamizar, G., Escalante, A., Aso, P.M., 2009. Molecular profiles of Venezuelan isolates of Trypanosoma sp. by random amplified polymorphic DNA method. Vet. Parasitol. 161 (3-4), 194-200.

Reid, S.A., Husein, D.B., 2001. Evaluation and improvement of parasitological tests for Trypanosoma evansi infection. Vet. Parasitol. 102, 291-297.

Scacchia, M., Cammà, C., Di Francesco, G., Di Provvido, A., Giunta, R., Luciani, M., Marino, A.M., Pascucci, I., Caporale, V., 2011. A clinical case of dourine in an outbreak in Italy. Vet. Ital. 47 (4), 473-475 469-72.

Sánchez, E., Perrone, T., Recchimuzzi, G., Cardozo, I., Biteau, N., Aso, P., M., Mijares, A., Baltz, T., Berthier, D., Balzano-Nogueira, L., Gonzatti, M.I., 2015a. Molecular characterization and classification of Trypanosoma spp. Venezuelan isolates based on microsatellite markers and kinetoplast maxicircle genes. Parasit. Vectors. 8 (1), 536.

Sánchez, E., Perrone, T., Recchimuzzi, G., Cardozo, I., Biteau, N., Aso, P.M.; Mijares, A., Baltz, T., Berthier, D., Balzano-Nogueira, L., Gonzatti, M.I., 2015b. Erratum to: molecular characterization and classification of Trypanosoma spp. Venezuelan isolates based on microsatellite markers and kinetoplast maxicircle genes. Parasit. Vectors 29 (October (8)), 566.

Smith, C.J., Levine, R.F., Mansfield, J.M., 1982. Cloning of African trypanosomes in mice immunosuppressed by cyclophosphamide treatment. Am. J. Trop Med. Hyg. 31 (6), 
1098-1102.

Spickler, A., Roth, J., Galyon, J., Lofstedt, J., 2009. Emerging and exotic diseases of animals. The Center for Food Security and Public Health. Iowa State University, USA 383pp.

Verdillo, J.C., Lazaro, J.V., Abes, N.S., Mingala, C.N., 2012. Comparative virulence of three Trypanosoma evansi isolates from water buffaloes in the Philippines. Exp. Parasitol. 130, 130-134.

Verducci, G., Perito, S., Rossi, R., Mannarino, E., Bistoni, F., Marconi, P., 1989. Identification of a trypanocidal factor against Trypanosoma equiperdum in normal human serum. Parasitology 98 (3), 401-407.
Vulpiani, M.P., Carvelli, A., Giansante, D., Iannino, F., Paganico, D., Ferri, N., 2013. Reemergence of dourine in Italy: clinical cases in some positive horses. J. Equine Vet. Sci. 33 (6), 468-474.

Wei, Y., Wen, Y.-Z., Desquesnes, M., Lun, Z.-R., 2011. Molecular epidemiology of Trypanosoma evansi and T. equiperdum and atypical human infection by animal Trypanosomes. The Molecular Epidemiology of Trypanosomes and Leishmania. Geoff Hide, Landes Biosciences and Springer Science, pp. 1-14.

Wen, Y.Z., Lun, Z.R., Zhu, X., Hide, G., Lai, D.H., 2016. Further evidence from SSCP and ITS DNA sequencing support Trypanosoma evansi and Trypanosoma equiperdum as subspecies or even strains of Trypanosoma brucei. Infect. Genet Evol. 41, 56-62. 